\title{
Mapping vote transition at the 2012 outset of the Catalan push for independence
}

\section{Puig \& J. Ginebra}

To cite this article: X. Puig \& J. Ginebra (2020): Mapping vote transition at the 2012 outset of the Catalan push for independence, Scottish Geographical Journal, DOI: 10.1080/14702541.2020.1792537

To link to this article: https://doi.org/10.1080/14702541.2020.1792537

册 Published online: 16 Jul 2020.

Submit your article to this journal $\Longleftarrow$

Q View related articles ¿

View Crossmark data $[\pi$ 


\title{
Mapping vote transition at the 2012 outset of the Catalan push for independence
}

\author{
X. Puig (D) and J. Ginebra \\ Department of Statistics and O.R., Technical University of Catalonia
}

\begin{abstract}
In 2012 Catalan politics came to a standstill, and a push for independence was triggered by a huge pro-independence rally. That push led, in 2017, to the Spanish government taking over the Catalan government, and top Catalan officials either going into exile or being jailed, tried, and convicted for sedition in 2019. This article investigates how Catalans switched their vote between the elections held shortly before and just after that 2012 rally, with a novel ecological inference approach that groups geographical areas based on the similarity/switching of vote patterns and estimates the vote-switch patterns for individuals in each group. This approach allows one to map how individual vote-switch patterns vary in space and estimate how the support for parties in favour and against independence shifted between these two elections.
\end{abstract}

\section{ARTICLE HISTORY}

Received 11 February 2020

Accepted 8 May 2020

\section{KEYWORDS}

Self-determination; ecological inference; Geographic clusters; political geography; vote switching distribution; regional geography

\section{Introduction}

Catalonia is a region in the north east of Spain, with a long history of attempts to break away from Spain going back three hundred years. The Catalan government was re-established in 1977, shortly after the return of democracy in Spain, and its parliament was reestablished in 1980. In its wake, Spain was soon organized around 17 'autonomous regional governments'. Ever since then, Catalan politics have focused on building up the Catalan government through often complicated negotiations with the Spanish government. As a result of this bargaining, the Spanish state has attained a certain level of decentralization, but Spain is not a federal state and lacks oa clear model of how to deal with differences in expectation around matters of regional governance and autonomy. Descriptions of Spanish political organization, in comparison with truly federal systems, can be found, for example, in Colomer (1998) and Downs (2003).

In 2003 the coalition party that had ruled Catalonia for 23 years, Convergència i Unió (CIU), was replaced by a leftist coalition government that came into power with the mandate of reforming the Catalan statute of autonomy. That process went sour when the Spanish government and parliament amended 120 articles of the statute that had been approved by the Catalan parliament, and with $88.9 \%$ of the parliamentarians in favour. The articles that were amended included the ones defining Catalonia as a 
nation; dealing with the control of ports and airports; requiring that the Catalan language be placed on a par with the Spanish language; soliciting a financial system that safeguarded against fiscal transfers that could lower the fiscal ranking of Catalonia; allowing Catalonia to become a separate voting entity in European Elections instead of being just part of a single Spanish entity; shielding Catalan government powers from central intrusion; and creating a justice council for Catalonia. For details about this statute reform process, see Keating and Wilson (2009), Orte and Wilson (2009) and Muro (2009).

The fact that in 2010 the Spanish constitutional court amended a further 14 articles, in spite of an original round of reform having already been approved in a referendum in 2006, with $73.9 \%$ of the popular vote in favour, further alienated a large part of the Catalan constituency. These further articles amended by the court included ones concerning: the organization of referendums; the decentralization of justice; Catalan as the preferred language in the administration; territorial organization; and the handling and integration of immigrants.

At that point a plurality of individuals and groups in Catalonia were in favour of pushing either for more Catalan self-rule or for out-right independence, with only a minority being more or less content with the way things were. Serrano (2013a, 2013b) argues that these constitutional developments had shown that attitudes towards independence and questions of identity were very complex. By then, independence received support even among individuals who also expressed a strong sense of Spanish identity. At the same, Guibernau $(2013,2014)$ discussed the origins of modern Catalan nationalism, the reasons behind the qualitative shift from pushing for devolution to pushing for secession, and the impediments to a self-determination referendum.

Consequently, on September 11 of 2012 the devolution process came to a standstill, and a credible push for independence was triggered by a huge pro-independence rally that was followed by huge rallies. Such rallies continued to be held thereafter on this date. The fact that 14 new states have been created in Europe since 1990, together with the independence referendum held in Scotland in 2014, led many Catalans to believe that there might be a window of opportunity to obtain independence for Catalonia. Eventually, a Catalan independence referendum was held being held in 2017 under the auspices of the Catalan Government. The Spanish police cracked down on that referendum, however, and the Catalan Government was temporarily taken over by the Spanish Government, Top Catalan officials either went into exile, or were jailed, tried and convicted for sedition in 2019.

To help assess how this turning point in Catalan politics affected the way in which national and ideological factors combine to influence the way in which Catalans vote and switch their vote, we seek to estimate the way in which Catalans switched their vote between the elections for the Catalan parliament held in 2010 and in 2012: that is, shortly before and just after the 2012 huge pro-independence rally that triggered this push for Catalan independence.

The analysis is based on the results of the elections broken down into small geographical areas, and hence one needs to extract information about individual voting behaviour from aggregate-level data. The ecological inference analysis used to do this adapts models, presented in Puig and Ginebra (2014a, 2015), that allow one to simultaneously do a Bayesian cluster analysis, grouping together geographical areas with similar vote and vote-switch behaviour, and an ecological inference analysis, estimating the way in 
which individuals in an area of that group switch their vote between the first and the second election.

By proceeding in this manner, Catalonia is partitioned into four clusters, which turn out to have a strong geographical meaning, and one finds both an overall vote-switch pattern in Catalonia as well as the vote patterns and vote-switch patterns in each one of these four clusters. This approach helps to describe how vote-switch patterns change with location, which is important in our case because Catalonia has a highly demographically fragmented population that leads to very different political behaviour depending on where people live.

The article is organized as follows. Section 2 presents the results of the 2010 and 2012 elections for the Catalan parliament and the method we are using to analyze them. Section 3 presents the four clusters in which the model partitions Catalonia, and their voting and vote-switch patterns, together with an overall assessment of the vote-switch pattern. The focus will be on the size of the shifts between parties that are in favour of, and against, holding a self-determination referendum (and abstentions), and how these shifts vary in space. The vote shifts between these two elections are also compared with the shifts between the same 2010 election and the 2011 election for the Spanish parliament, to check whether the two-dimensional (identity versus ideology) competition prevalent in Catalonia fares differently in these two scenarios close in time.

\section{Materials and methods}

\subsection{The elections}

The two elections for the Catalan parliament considered here were held on 28 November 2010 and 25 November 2012. The estimation of the way in which individuals switched their vote between these elections will be made based on the election results aggregated into nine categories and broken down into 1461 small areas.

Outside the city of Barcelona these areas are districts, and they coincide with municipalities only where they are small. Almost all municipalities with more than 10,000 inhabitants, and some smaller than that, are broken down into more than one district. Barcelona, which is the main city in Catalonia with close to $22 \%$ of its population, is broken down into only 10 districts, which are much larger than districts elsewhere. As a consequence, an enlarged map of Barcelona will be presented as an inset of the map of Catalonia, and there we rely on its 233 basic statistical areas instead of its districts, because they have sizes comparable with districts elsewhere.

Seven categories in the 2010 election correspond to the parties that obtained seats, which were: Convergència $i$ Unió, labelled CIU; Partit dels Socialistes de Catalunya, PSC; Partit Popular de Catalunya, PPC; Esquerra Republicana de Catalunya, ERC; Iniciativa per Catalunya-Verds, ICV' Ciutadans, Cs; and Solidaritat per la Independència, SI. In the 2012 election SI lost all of its seats but a new contender, the Candidatures d'Unitat Popular, CUP, gained them and it replaces SI as the seventh category in that election.

All the votes for small parties that did not obtain seats, along with blank and null votes, are combined into an eighth category, labelled others. In 2010 the largest contributors to others were blank votes, a right-wing anti-immigration party, and a staunch pro-independence party. In 2012 the largest contributors were the same right-wing party, blank votes, 
and SI. The ninth category is the number of voting age individuals in each area that did not vote, abs. Table 1 presents the overall election results.

There is a strong two-dimensional competition prevalent in all the elections in Catalonia, involving identity and ideology, and investigated, for example, by Balcells (2007). At that time, on the identity scale the main parties could be ordered from being more inclined to seceding from Spain to being more inclined towards strengthening the union with Spain: in the order, SI, CUP, ERC, CIU, ICV, PSC, PPC and Cs. In fact, the last three parties were clearly pro-union, while the first five basically only contended for the vote in Catalonia and were in favour of the right of Catalonia to hold a self-determination referendum.

On the ideological scale, one could order them from being more conservative to being more progressive: in the order, PPC, CIU, Cs, PSC, SI, ERC, ICV and CUP. Figure 1 locates the stand of typical voters associated with these parties on both these ideological and identity scales. This assessment is based on the average results of the survey made on November of 2012 by the 'Centre d'Estudis d'Opinió'.

CIU has held the plurality of the seats in the Parliament ever since it was restored in 1980, and before 2012 PSC always came in second. The Catalan government was held by CIU from 1980 to 2003, and by a leftist coalition of PSC, ERC and ICV from 2003 to 2010. In $2010 \mathrm{CIU}$ regained the Catalan government.

The 2012 election was held two years earlier than expected as a consequence of the huge pro- independence demonstration of September 11 of that year, and for the first-time

Table 1. Overall results in the 2010 and 2012 elections for the Catalan parliament. The corresponding percentages are the overall percentages in Table 2.

\begin{tabular}{ccccccccccc}
\hline & CIU & PSC & PPC & ERC & ICV & Cs & SI & others & abs & $N$ \\
\hline 2010 & $1,198,193$ & 570,405 & 384,470 & 218,152 & 229,853 & 105,884 & 102,193 & 326,045 & $2,094,678$ & $5,229,873$ \\
& CIU & PSC & PPC & ERC & ICV & Cs & CUP & others & abs & $N$ \\
\hline 2012 & $1,112,341$ & 523,333 & 471,197 & 496,292 & 358,857 & 274,925 & 126,219 & 294,286 & $1,600,510$ & $5,257,960$ \\
\hline
\end{tabular}

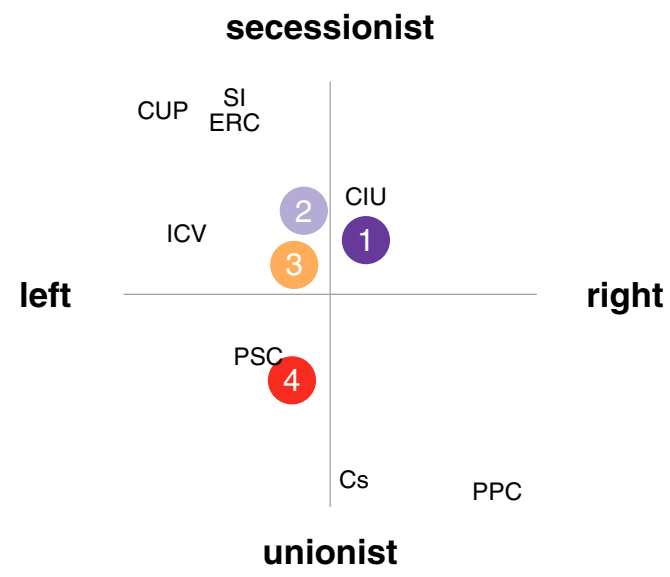

Figure 1. Standing of a typical voter of each party and of each one of the clusters estimated in Section 3 on the ideological versus national identity plane at the time of these elections. 
parties were explicit about whether they were in favour of, or opposed, holding a selfdetermination referendum. That election was intended as a check of the strength of the pro-independence movement, and, consequentially, abstention was much lower than usual for an election for the Catalan parliament. The surprise was that even though CIU was still the clear winner, and PSC still came in second, the vote count for CIU and for PSC was lower than in 2010, in spite of the large increase in participation. The main beneficiaries of this drop, and of the overall increase in participation, were mainly the ERC, Cs and CUP, which are placed at the far ends of the independence question.

The 2012 elections thus created a new political map and triggered a heated debate about the way in which voting age individuals switched their vote or switched from abstention into voting between 2010 and 2012. Using survey data, Rico and Liñeira (2014) explore the conversion in this 2012 election of a large part of Catalan voters towards favouring independence - a position which, until then, had been regarded as a rather extreme position. They also describe the context, the campaign, the result and the immediate consequences of that election.

Figure 2 summarizes these results by mapping the proportion of the vote in both elections for three combination of parties and abstainers. An enlargement of the map of Barcelona, where $22 \%$ of Catalan population lives, is presented to help appreciate the voting behaviour there. Note that there is a strong relationship between how individuals vote and where they live. Note also the decrease of abstention and the increase of pro-secession votes between these elections everywhere in the map.

Lepic (2017) discusses of how the spatial distribution of the Catalan nationalist vote evolved between 1985 and 2015, and how that vote correlates with socio-demographic covariates. Lepic shows that the 2010-2012 elections were a watershed in the level of support for the Catalan nationalist vote, and it partitions Catalonia into spatial modes. Rodon and Guinjoan (2018) shows that in Catalonia the relationship between identity and support for independence depends on the context in which individuals interact, on socio-demographic composition, and particularly on where they live.

\subsection{Methods}

The analysis carried out here reconstructs individual voting behaviour from aggregate data, which is what characterizes ecological inference problems. Good overviews of the approaches available for that problem can be found in Cleave et al. (1995), King (1997, 2000), Johnston and Pattie (2001, 2003), Freedman (2001) and Glynn and Wakefield (2010). Usually vote-switch patterns are estimated through ecological regression models, early on using fixed coefficients (see, e.g. Goodman, 1953, 1959; Hawkes, 1969; Miller, 1972), and more recently with random coefficients (see, e.g. Brown \& Payne, 1986; O’Loughlin, 2000; Rosen et al., 2001; Wakefield, 2004; or Greiner \& Quinn, 2009).

These models either assume that all the areas are exchangeable, or they distinguish areas by modelling the coefficients of the model through area level covariates. The exchangeability assumption forces that all the coefficients of the ecological regression model either be the same for all the areas (when using fixed coefficient models), or at least that coefficients share the same distribution for all the areas (when using random coefficient models). In our case, the maps in Figure 2 and the literature make it clear that the election results in Catalonia are strongly related with location, and hence using standard 

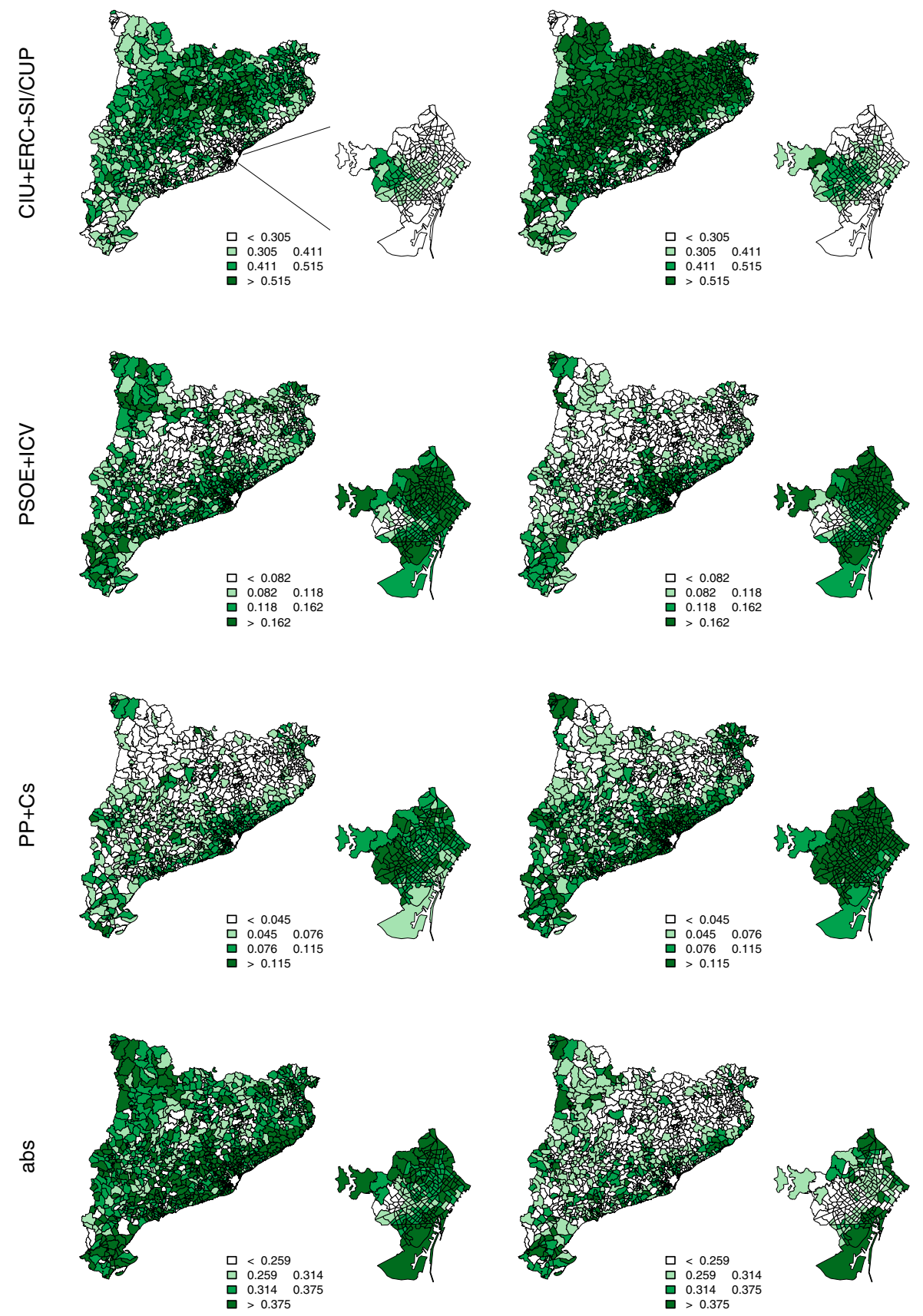

Figure 2. Maps of the proportion of the vote in Catalonia for pro-secession parties (CIU + ERC $+\mathrm{SI}+$ CUP), for leftist non-secessionist parties (PSOE + ICV), for conservative non-secessionist parties (PP + Cs), and the abstention vote in the 2010 and 2012 elections. The inset on the right is an enlargement of the map of the city of Barcelona. 
ecological regression models making that 'constancy' assumption would be questionable. Furthermore, area level covariates are not available, because we are dealing with districts and not municipalities.

Accordingly, we will be using an approach that embeds a Bayesian ecological inference model into a Bayesian cluster analysis model to create a single model for the results of the two elections at once. In this setting, the parameters of the ecological inference part of the model will be constant or share the same distribution only among areas in the same cluster. In that way, the method simultaneously groups areas into a small number of clusters, each with a different voting pattern and vote-switch pattern, and it links the two election results through one vote-switch matrix per cluster that determines the voting pattern of an area in the second election starting from its first election results. By proceeding in that way, one improves the estimation of the vote-switch patterns in each area by only pulling in information for areas that are similar, and by doing that one also improves the estimation of the global vote-switch matrix. This approach also allows one to summarize the spatial variation of individual vote-switch behaviour through a small number of vote-switch matrices.

The number of clusters chosen is four, because it is the smallest number under which the model could simulate data with a spatial variation and correlation similar to the actual election results, and because the corresponding four-cluster model leaves little spatial correlation in the residuals of the model. A sketch of the model used can be found in an Appendix and a detailed description of the model can be found in Puig and Ginebra (2015). Details on the way in which the number of clusters is chosen and the corresponding model is checked through posterior predictive checks can be found in Puig and Ginebra (2014a, 2014b) and in Robertson et al. (2014).

\section{Results}

\subsection{Spatial variation of voting patterns}

Table 2 presents the percentage of the vote for each option in each election and each one of the four clusters into which Catalonia is partitioned by the model, together with the relative size of these clusters. Cluster labels have been chosen so that they increase with the increasing percentage of abstention and of the vote for PSC, and with the decreasing percentage of the vote for CIU, which are the three main categories. That leads to clusters

Table 2. Percentage of vote for each option in each cluster, and the relative size of clusters in number of areas (\%Ar) and of voting age individuals (\%Pop).

\begin{tabular}{rccrrrrrrrrrrr}
\hline Elect & Cluster & CIU & PSC & PPC & ERC & ICV & Cs & SI & CUP & others & abs & $\% A r$ & $\% P o p$ \\
\hline 2010 & 1 & 28.4 & 8.9 & 8.5 & 4.1 & 5.0 & 2.4 & 2.3 & - & 6.0 & 34.4 & 11.8 & 15.2 \\
& 2 & 25.4 & 9.8 & 6.1 & 5.0 & 3.4 & 1.4 & 2.5 & - & 6.6 & 39.7 & 52.3 & 29.4 \\
& 3 & 22.5 & 10.8 & 7.3 & 4.4 & 4.7 & 2.0 & 2.0 & - & 6.3 & 40.2 & 25.0 & 31.6 \\
& 4 & 16.8 & 13.7 & 8.4 & 2.9 & 4.8 & 2.6 & 1.0 & - & 5.8 & 43.9 & 10.8 & 23.8 \\
& Overall & 22.9 & 10.9 & 7.4 & 4.2 & 4.4 & 2.0 & 2.0 & & 6.2 & 40.1 & 100.0 & 100.0 \\
2012 & 1 & 26.7 & 7.3 & 9.9 & 9.7 & 7.0 & 5.6 & - & 2.7 & 5.0 & 26.2 & 11.8 & 15.2 \\
& 2 & 25.4 & 8.7 & 7.6 & 11.1 & 5.2 & 3.9 & - & 2.5 & 5.4 & 30.2 & 52.3 & 29.5 \\
& 3 & 20.8 & 9.4 & 8.8 & 9.8 & 7.1 & 5.1 & - & 2.6 & 5.6 & 30.9 & 25.0 & 31.6 \\
& 4 & 12.8 & 14.0 & 10.2 & 6.7 & 8.4 & 6.9 & - & 1.8 & 6.2 & 32.9 & 10.8 & 23.7 \\
& Overall & 21.2 & 10.0 & 9.0 & 9.4 & 6.8 & 5.2 & - & 2.4 & 5.6 & 30.4 & 100.0 & 100.0 \\
\hline
\end{tabular}


shifting from more conservative to more progressive when one goes from Cluster 1 to Cluster 4.

Figure 3 presents the map with areas classified into these four clusters. Even though the model does not use the spatial location of the areas, these clusters have a spatial dependence, and can be characterized through the socioeconomic and demographic composition of their population. This helps interpret the vote patterns and vote-switch patterns associated with them. Ideally, that link between the cluster structure and the underlying socioeconomic composition of the corresponding areas should be assessed by incorporating into the analysis contextual variables measured at district level, but that information is not available because districts are municipalities only for small municipalities. Nevertheless, that relationship will be clear to anyone familiar with the demography in Catalonia. In fact, note that the cluster structure estimated here is very similar to the one estimated in Puig and Ginebra (2015) based on vote shifts between Catalan and Spanish elections in Catalonia, which means that it reflects a pervading underlying demographic reality.

Cluster 1 is the smallest in population, and close to the smallest in number of areas, and it is formed by the wealthiest and most conservative districts, mostly in Barcelona. Cluster 2 has more than one half of all the areas considered (but none in Barcelona) and is formed by villages and small towns in the mostly Catalan speaking interior of Catalonia.

Cluster 3 is the most populated and the most heterogeneous one, and it groups mostly urban districts in and around Barcelona, that are more to the left than the first two clusters, and, there, Catalan and Spanish identities co-exist more evenly. Cluster 4 is the smallest in number of areas and is formed mainly by working class areas in Barcelona and its industrial belt, which have the smallest proportion of individuals having Catalan as their mother tongue and the largest proportion of immigrants, both from Spain and other parts of the world.

Figure 1 places the typical voters in each cluster on the national and ideological allegiance plane. From now on it will help recognize Cluster 1 as the most conservative one, Cluster 2 as the most pro-independence one, Cluster 3 as the most moderate and heterogeneous one, and Cluster 4 as the most progressive and pro-union of all.

\subsection{Spatial variation of vote-switch patterns}

To describe the vote-switch patterns at a local level we rely on the four vote-switch matrices, presented in Figure 3. The rows of these matrices add up to 100, and they are the estimated distribution of the vote in the 2012 election of all the individuals in the corresponding cluster known to have voted for a given option in the 2010 election.

To summarize the way in which all individuals in Catalonia vote switch in each pair of elections, we will resort to the overall vote-switch matrix of Figure 4. It is computed by combining the four vote-switch matrices in Figure 3 into a single weighted average matrix that weights each matrix according to the population size of the corresponding cluster. An alternative way of summarizing the overall vote-switching behaviour is through the joint distribution of the vote in these two elections, in Figure 5.

The first thing that one notices in Figure 3 is how different the four vote-switch matrices are, and so on how much spatial variation there is in vote transition behaviour. Next, we comment on some of the most relevant distinctive features in these matrices. 


\section{2}

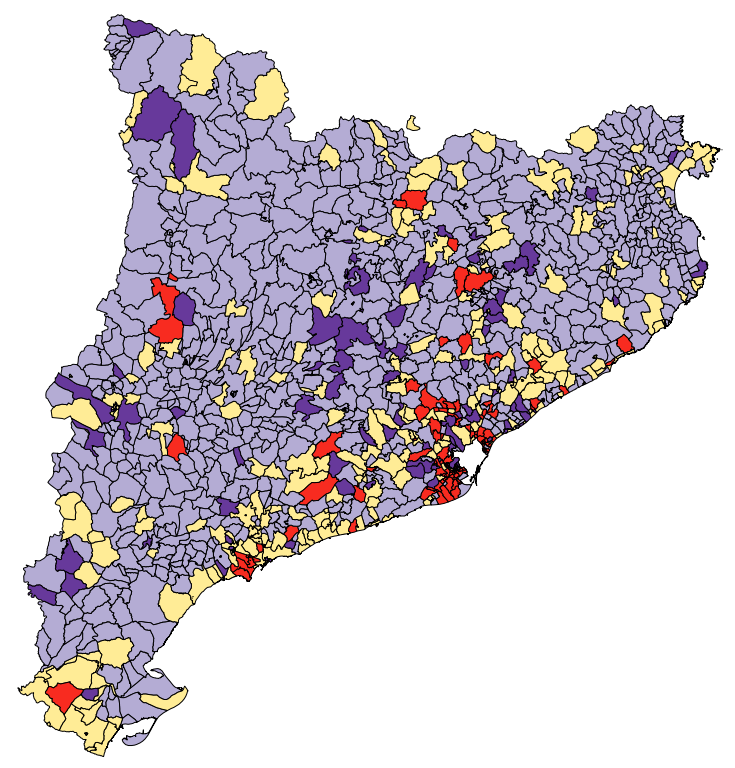

Cluster

$\square 1$ conservative \& pro secession

$\square 2$ pro secession

$\square 3$ mixed

$\square 4$ progressive \& pro union

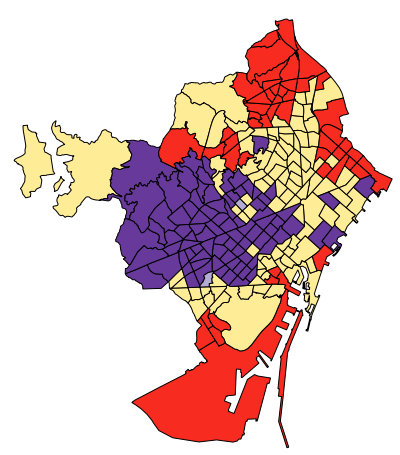

Cluster 1: conservative \& pro secession 2012

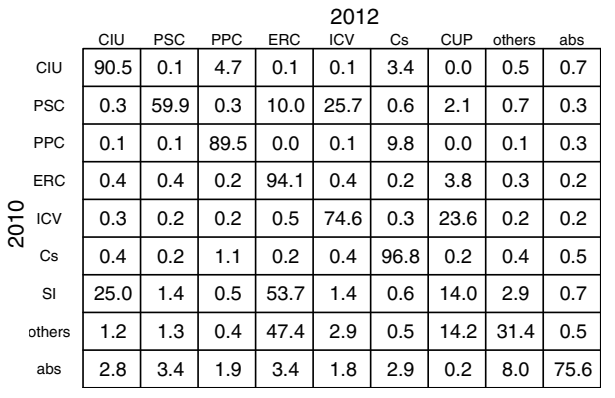

\begin{tabular}{|c|c|c|c|c|c|c|c|c|c|}
\hline & \multicolumn{9}{|c|}{ Cluster 2: pro secession } \\
\hline & CIU & PSC & PPC & ERC & $\begin{array}{l}201 \\
\mathrm{ICV}\end{array}$ & Cs & CUP & other & \multirow{2}{*}{$\begin{array}{l}\text { abs } \\
0.1\end{array}$} \\
\hline CIU & 92.9 & 0.0 & 0.1 & 5.8 & 0.1 & 0.1 & 0.1 & 0.8 & \\
\hline PSC & 0.3 & 57.1 & 3.4 & 6.6 & 8.7 & 0.4 & 1.8 & 3.9 & 17.8 \\
\hline PPC & 0.2 & 0.5 & 87.2 & 0.2 & 1.2 & 6.9 & 0.2 & 2.7 & 0.9 \\
\hline \multirow{3}{*}{ 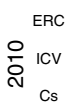 } & 2.0 & 0.1 & 0.1 & 92.8 & 0.1 & 0.1 & 3.9 & 0.6 & 0.3 \\
\hline & 0.2 & 0.2 & 0.2 & 0.4 & 63.6 & 4.0 & 30.7 & 0.4 & 0.2 \\
\hline & 0.3 & 0.6 & 0.5 & 0.3 & 0.9 & 96.5 & 0.3 & 0.4 & 0.3 \\
\hline \multirow{3}{*}{$\begin{array}{c}\text { SI } \\
\text { others }\end{array}$} & 23.3 & 0.1 & 0.2 & 44.9 & 0.3 & 0.8 & 14.0 & 16.2 & 0.2 \\
\hline & 49.9 & 0.1 & 0.4 & 22.9 & 0.4 & 0.2 & 13.9 & 12.0 & 0.2 \\
\hline & 1.5 & 2.5 & 3.7 & 8.0 & 3.0 & 1.4 & 0.7 & 8.0 & 71.1 \\
\hline
\end{tabular}

Cluster 3: mixed

\begin{tabular}{|c|c|c|c|c|c|c|c|c|c|}
\hline & \\
\hline & $\mathrm{CIU}$ & PSC & PPC & ERC & ICV & Cs & CUP & others & abs \\
\hline $\mathrm{ClU}$ & 80.9 & 0.2 & 1.3 & 13.2 & 0.3 & 0.2 & 0.0 & 3.8 & 0.1 \\
\hline PSC & 0.1 & 67.2 & 0.5 & 0.8 & 17.3 & 6.4 & 0.2 & 7.4 & 0.1 \\
\hline PPC & 0.1 & 0.1 & 79.1 & 0.1 & 0.1 & 20.3 & 0.0 & 0.2 & 0.1 \\
\hline ERC & 0.4 & 0.1 & 0.1 & 95.9 & 0.2 & 0.1 & 3.1 & 0.1 & 0.1 \\
\hline ICV & 0.1 & 0.0 & 0.1 & 0.1 & 89.0 & 0.2 & 10.4 & 0.1 & 0.1 \\
\hline Cs & 0.1 & 0.1 & 0.1 & 0.1 & 0.2 & 99.1 & 0.1 & 0.1 & 0.1 \\
\hline SI & 59.4 & 0.2 & 0.2 & 2.5 & 0.2 & 0.2 & 36.8 & 0.2 & 0.3 \\
\hline others & 4.4 & 0.5 & 0.5 & 38.8 & 7.3 & 1.0 & 19.5 & 27.6 & 0.4 \\
\hline abs & 1.9 & 5.6 & 6.6 & 0.3 & 1.0 & 1.8 & 0.0 & 5.4 & 77.4 \\
\hline
\end{tabular}

\begin{tabular}{|c|c|c|c|c|c|c|c|c|c|}
\hline \multirow[b]{2}{*}{$\mathrm{CIU}$} & \multicolumn{9}{|c|}{ Cluster 4: progressive \& pro union } \\
\hline & $\frac{\mathrm{CIU}}{62.0}$ & $\begin{array}{c}\text { PSC } \\
0.1\end{array}$ & $\frac{P P C}{0.2}$ & $\frac{\text { ERC }}{19.2}$ & $\frac{\mathrm{ICV}}{4.5}$ & $\frac{\mathrm{Cs}}{12.1}$ & $\frac{\text { CUP }}{1.6}$ & others & $\frac{a b s}{0.1}$ \\
\hline PSC & 0.0 & 75.5 & 2.6 & 0.1 & 13.9 & 5.5 & 0.5 & 1.5 & 0.1 \\
\hline PPC & 0.1 & 0.1 & 98.1 & 0.1 & 0.3 & 0.8 & 0.1 & 0.2 & 0.1 \\
\hline ERC & 1.0 & 0.1 & 0.2 & 83.8 & 0.4 & 0.2 & 13.9 & 0.2 & 0.2 \\
\hline ICV & 0.1 & 0.1 & 0.1 & 0.2 & 95.9 & 0.2 & 3.1 & 0.2 & 0.1 \\
\hline Cs & 0.2 & 0.3 & 0.3 & 0.3 & 0.7 & 97.2 & 0.4 & 0.5 & 0.2 \\
\hline SI & 81.3 & 0.4 & 0.7 & 8.3 & 0.7 & 0.5 & 6.9 & 0.6 & 0.6 \\
\hline others & 0.2 & 0.7 & 0.4 & 0.8 & 8.4 & 3.7 & 6.6 & 79.1 & 0.2 \\
\hline abs & 0.0 & 9.6 & 3.6 & 0.9 & 1.9 & 4.5 & 0.5 & 3.8 & 75.2 \\
\hline
\end{tabular}

Figure 3. Classification of the 1461 areas of Catalonia into four clusters, and corresponding vote-switch matrices. The inset map on the right corresponds to an enlargement of the map of Barcelona. The rows of these matrices add up to 100, and are the distributions of the vote in 2012 of individuals who chose a given option in 2010. 


\begin{tabular}{|c|c|c|c|c|c|c|c|c|c|}
\hline & \multicolumn{9}{|c|}{ Destination of the 2010 vote } \\
\hline & & & & & 201 & & & & \\
\hline & $\mathrm{CIU}$ & PSC & PPC & ERC & $\mathrm{ICV}$ & Cs & CUP & others & abs \\
\hline $\mathrm{ClU}$ & 81.7 & 0.2 & 1.8 & 8.7 & 1.2 & 4.0 & 0.3 & 1.9 & 0.2 \\
\hline PSC & 0.2 & 67.0 & 1.6 & 3.5 & 16.1 & 2.8 & 0.8 & 3.2 & 4.8 \\
\hline PPC & 0.1 & 0.2 & 88.6 & 0.1 & 0.4 & 9.4 & 0.1 & 0.8 & 0.3 \\
\hline ERC & 1.1 & 0.3 & 0.2 & 91.3 & 0.4 & 0.2 & 5.6 & 0.5 & 0.3 \\
\hline ICV & 0.2 & 0.2 & 0.2 & 0.3 & 80.1 & 2.1 & 16.4 & 0.3 & 0.2 \\
\hline Cs & 0.1 & 0.3 & 0.4 & 0.1 & 0.4 & 98.0 & 0.1 & 0.3 & 0.2 \\
\hline SI & 46.6 & 0.6 & 0.5 & 22.9 & 0.7 & 0.7 & 20.1 & 7.5 & 0.4 \\
\hline others & 16.9 & 1.1 & 0.6 & 29.3 & 6.0 & 1.5 & 13.3 & 30.9 & 0.4 \\
\hline abs & 1.3 & 6.0 & 4.3 & 2.6 & 2.0 & 2.5 & 0.2 & 6.4 & 74.6 \\
\hline
\end{tabular}

Figure 4. The rows of the matrix add up to 100, and they are the estimated overall distributions of the vote in 2012 of all the individuals who chose a given option in 2010.

Joint Distribution of the 2010 and 2012 vote

\begin{tabular}{|c|c|c|c|c|c|c|c|c|c|}
\hline & \multicolumn{9}{|c|}{2012} \\
\hline & CIU & PSC & PPC & ERC & ICV & Cs & CUP & others & abs \\
\hline CIU & 980 & 2 & 21 & 105 & 15 & 48 & 3 & 23 & 3 \\
\hline PSC & 1 & 384 & 9 & 20 & 92 & 16 & 5 & 18 & 27 \\
\hline PPC & 0 & 1 & 345 & 0 & 2 & 37 & 0 & 3 & 1 \\
\hline ERC & 2 & 1 & 1 & 193 & 1 & 0 & 12 & 1 & 1 \\
\hline ICV & 0 & 1 & 0 & 1 & 183 & 5 & 37 & 1 & 0 \\
\hline Cs & 0 & 0 & 0 & 0 & 0 & 109 & 0 & 0 & 0 \\
\hline $\mathrm{SI}$ & 47 & 1 & 1 & 23 & 1 & 1 & 20 & 8 & 0 \\
\hline others & 56 & 3 & 2 & 96 & 20 & 5 & 44 & 102 & 1 \\
\hline abs & 27 & 125 & 90 & 54 & 42 & 53 & 5 & 135 & 1563 \\
\hline
\end{tabular}

Figure 5. Estimated overall joint distribution in thousands of votes.

\subsubsection{What did 2010 abstainers do in 2012?}

Abstention is by far the largest category in both elections. The matrix in Figure 4 indicates that close to $25 \%$ of the individuals that abstained in 2010 did not abstain in 2012 . These more than half a million individuals played a crucial role in determining the outcome of the 2012 election by contributing in different degrees to all parties in the game. 
The main single beneficiary, in 2012, of the vote of the 2010 abstainers was PSC, receiving the vote of about 125,000 abstainers, and the second largest single beneficiary was PPC, receiving the vote of about 90, 000 of them. According to Figure 3, these new PSC and PPC voters, together with the 53,000 of the 2010 abstainers estimated to have voted for Cs in 2012, are mainly from Clusters 3 and 4 where abstention is always larger, and the Spanish sense of identity is stronger. All together, these 268,000 voters correspond to pro-union individuals who typically did not vote in Catalan elections but in 2012 made an exception and voted for pro-union parties, in spite of them being regional elections given what could have been at stake in that election.

On the other side of the national divide, the main beneficiary from the vote of the 2010 abstainers was ERC, receiving the vote of about 54,000 of them, coming mostly from the pro-independence-leaning Cluster 2, together with ICV, receiving the vote of about 42,000 of them. CIU received only about 27,000 votes from these votes in spite of being the clear winner in that election. Overall, only 86,000 switched from abstaining in 2010 to voting for parties supporting independence.

\subsubsection{Main vote-switch trends}

The clear winner in both elections was CIU, but in 2012 it lost votes in spite of the important increase in participation. About $82 \%$ of the 2010 voters for CIU repeated their vote in 2012, but it lost close to 105,000 of its 2010 votes to ERC, 48,000 to Cs and a little less than 21,000 to PPC. The fidelity to CIU was highest in Clusters 1 and 2, with most of its defectors voting PPC in the conservative Cluster 1, and most of them voting ERC in Clusters 2 and 3. In the most left leaning and pro-union Cluster 4 only an estimated $62 \%$ repeated their vote for CIU, with close to $20 \%$ of its defectors switching to ERC, and $12 \%$ switching to the pro-union Cs. Overall, CIU lost about 71,000 voters to pro-union parties and about 108,000 voters to other pro-independence parties.

In both elections the second party in votes was PSC, but in 2012 it also lost votes in spite of the increase in participation and of the large number of 2010 abstainers that voted for them. Overall, PSC retained only $67 \%$ of its voters (less than $60 \%$ in the two most proindependence Clusters 1 and 2), and lost about 92,000 votes to ICV, 27,000 to abstention, 20,000 to ERC and 16,000 to Cs. In Clusters 1, 3 and 4 most of its defectors voted ICV, and to a lesser extent ERC in Cluster 1 and Cs in Clusters 3 and 4, while in Cluster 2 most PSC defectors abstained, and, to a lesser extent, voted ICV and ERC.

ERC came in fifth in 2010 and third in 2012, and it is the party that gained the most. The fidelity to ERC is well above $90 \%$ everywhere except in Cluster 4, where close to $14 \%$ of its voters switched into voting for CUP, in line with CUP and Cluster 4 being the ones leaning more towards the left.

Finally, it is quite remarkable that two thirds of all the 2010 voters counted under others, shifted into voting for parties in favour of Catalan self-determination: 96,000 shifted into voting for ERC, with almost none of them coming from the pro-union Cluster 4; 56,000 shifted into voting for CIU, almost all coming from the pro-secession Cluster 2; 44,000 shifted into voting for CUP; and 20,000 shifted into voting for ICV. Almost none of the 2010 voters counted under others shifted into voting for the prounion PSC, PPC or Cs. These vote shifts in favour of pro-secession parties were crucial in helping offset the imbalance in the vote of 2010 abstainers in favour of pro-union parties. 


\subsubsection{Shifts between parties for and against self-determination}

The 2012 election was the first one in which all parties made explicit their position regarding the possibility of holding a self-determination referendum. To help assess how all the shifts relate to the Catalan self-determination process in place at the time, the shifts for all the parties that were clearly in favour of holding a self-determination referendum, which were CIU, ERC, ICV, SI and CUP, and the shifts for all the parties that were against holding that referendum, namely PSC, PPC and Cs, can be aggregated. Overall, the parties in favour of holding such a referendum gathered $61 \%$ of the vote in 2010 , against $60 \%$ in 2012, but this apparent stability in the overall percentage was the result of the significant underlying shifts described next.

The flow chart in Figure 6 presents these overall shifts. Itis estimated that in the 2012 election, just six weeks after the pro-independence rally, the pro-referendum parties received the vote of 215,000 individuals that had voted blank, null or for extra-parliamentary parties in 2010, while the against-referendum parties barely received any votes from individuals in that category. About 128,000 of the 2010 abstainers voted for the pro-referendum parties in 2012, while close to 268,000 voted for the againstreferendum parties.

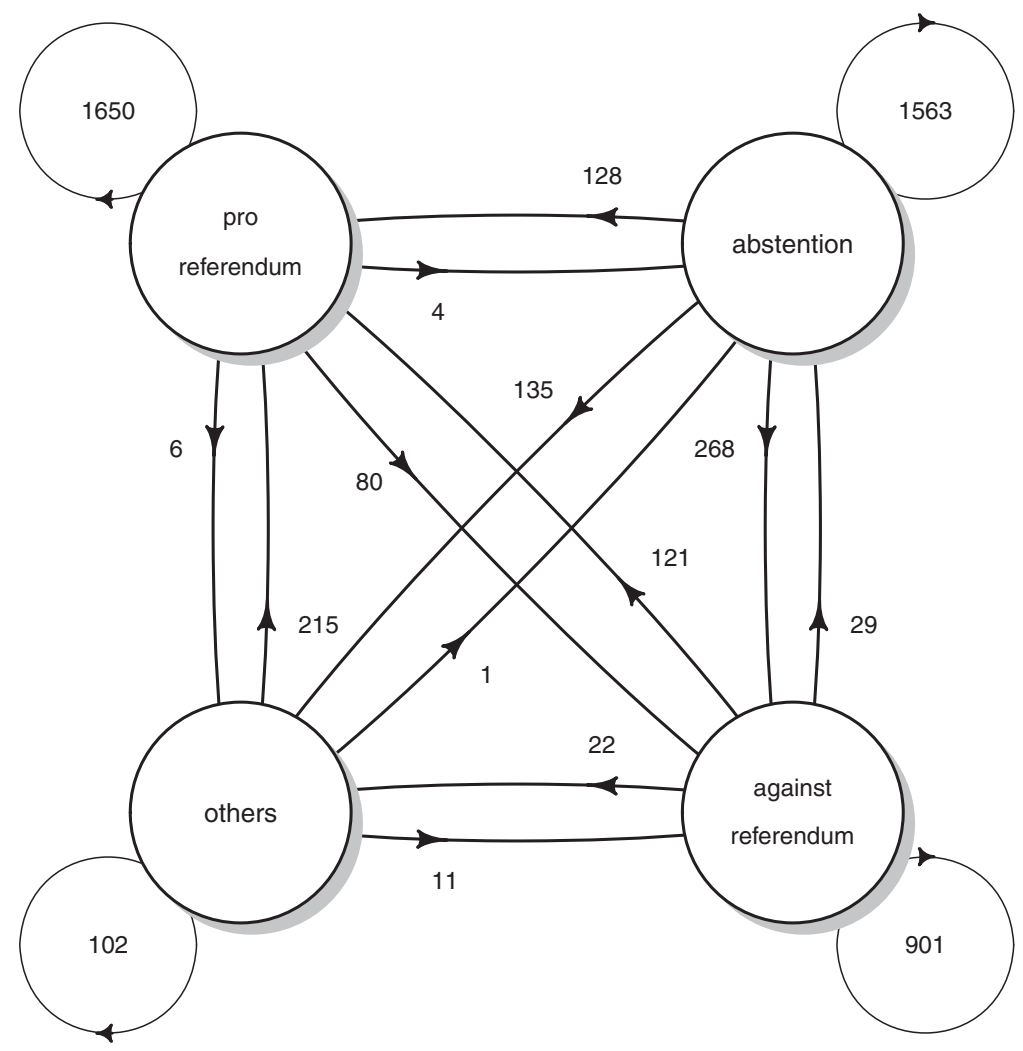

Figure 6. Flow chart with the estimated shifts, in thousands of votes, between the pro-referendum parties (CIU, ERC, ICV, SI and CUP), the against-referendum parties (PSC, PPC and Cs), others (blank, null and extra-parliamentary), and abstention. Here, in $2012 \mathrm{SI}$ is counted as pro-referendum and not as others (as done elsewhere). 
It is also estimated that 121,000 individuals who, in 2010 , had voted for parties that were against a referendum, in 2012 voted for pro-referendum parties (almost all of them were PSC voters switching to ICV everywhere, and switching to ERC in Clusters 1 and 2). In the opposite direction, close to 80,000 individuals who in 2010 had voted for pro-referendum parties, in 2012 voted for parties now against a referendum (almost all are CIU voters switching to Cs in Clusters 1 and 4 and switching to PPC in Cluster 1). The only party estimated to have lost a significant number of 2010 voters to abstention was the PSC, losing a little under 30,000 votes in that way (almost all in the most pro-independence Cluster 2).

Overall, it is estimated that in 2012 the pro-referendum parties obtained about 464,000 votes coming from individuals that had not voted for them in 2010 and lost the vote of about 90,000 individuals who had voted for them in 2010. In comparison, the againstreferendum parties in 2012 gained about 359,000 votes from individuals who had not voted for them in 2010 and lost about 172,000 votes from individuals who had voted for them.

\subsubsection{Did voters behave in 2012 as in the 2011 general election?}

The role played by national allegiance is weaker or stronger than the role played by ideology depending on the scope of the election at hand. Balcells (2007) investigates how these two dimensions interact in the elections for the Catalan parliament.

Liñeira (2011) and Puig and Ginebra (2015) explore mechanisms that explain the differences in voting patterns in elections for the Catalan and for the Spanish parliament as a consequence of the different roles played by these two dimensions. They involve a different voter turnout effect, induced by unionists abstaining in elections for the Catalan parliament and by secessionists abstaining in elections for the Spanish parliament; and a strategic dual vote effect, induced by individuals switching from pro-union (Spanish wide) parties to pro-secession (Catalan wide) parties, and vice versa, depending on the scope of the election.

Both the 2010 and 2012 elections were for the Catalan parliament, but the participation in 2012 was much closer to the one in elections for the Spanish parliament, which tend to be higher. Here, the vote-shifts between 2010 and 2012 will be compared with the ones between the same 2010 election and the 2011 election for the Spanish parliament estimated in Puig and Ginebra (2015).

In terms of voter turnout, one finds a large net flow of individuals switching from abstaining in 2010 into voting for the pro-union parties both between 2010 and 2011 as well as between 2010 and 2012. Nevertheless, 425,000 individuals are estimated to have vote-switched in this way in 2011 , but only 268,000 in 2012 . Furthermore, where it was estimated that close to 105,000 individuals voting in 2010 for the pro referendum CIU or ERC ended up abstaining in the 2011 election, here one finds a net flow of 124,000 going in the opposite direction, from abstaining in 2010 into voting either for CIU or for ERC in 2012.

In terms of dual vote, there was a net flow of 40,000 individuals switching from CIU or ERC in 2010 into the pro-union PSC in 2011, but here one estimates more than 20,000 switching in the opposite direction between 2010 and 2012. Note also that between 2010 and 2011 there was a net flow of 100,000 individuals switching from CIU into PPC, which was much larger than the 21,000 doing the same in 2012, and larger than 
the 48,000 that switched from CIU to Cs. And the flow of 215,000 switching from voting in 2010 for small parties into voting in 2012 for parties in favour of self-determination, is not found between 2010 and 2011.

\section{Discussion}

By using a novel ecological inference approach to vote-switching estimation, we have partitioned Catalonia into four clusters based both on the vote as well as on the voteswitch behaviour of their inhabitants. The main advantage of our approach is that it summarizes the spatial variation of vote switching through a small set of vote switch matrices, one for each cluster, instead of having to deal with as many different vote switch matrices as areas.

The 2012 election was the first one in which all parties made it explicit whether they were in favour or against independence, and of holding a self-determination referendum. Hence the importance of looking into how electors reacted to that change. After that election, parties have stuck to the position taken in 2012 with respect to self-determination, and the relative strength of parties on the two sides of the issue has remained rather stable. In the 2015 election to the Catalan parliament, overall support for the parties in favour of Catalan self-determination turned out to be 59\%, which is very close to the support in 2010 and 2012. And in fact, all sample surveys carried out by the 'Centre d'Estudis d'Opinió' in recent years consistently show that around $70 \%$ of all voting age individuals in Catalonia are in favour of holding such a referendum.

In Cluster 1, 2 and 3 the parties that are in favour of exercising the right of Catalan selfdetermination clearly win over the parties that are against it. In Cluster 4, amounting to less than one fourth of the Catalan population and comprising working class districts with the largest proportion of immigrant population born in Spain, the parties that are against Catalan self-determination have a small advantage over the ones that are in favour of it. Given that the four clusters found here are distinguishable based on their demographic characteristics, it is likely that the vote behaviour in a self-determination referendum would be spatially partitioned along similar lines.

At this point it would be risky to assume that all the support for exercising Catalan selfdetermination would translate into support for Catalan independence in a hypothetical binding referendum held under the auspices of the international community. But the outcome of the most recent elections indicate that the trend initiated in the fall of 2012 shifting voters away from nationally mixed parties towards parties adopting a clear-cut position on the national front has solidified. This, coupled with the lack of a credible middle way between maintaining the status quo and independence, might push most CIU, ERC and CUP voters, and a few of ICV and PSC voters, into eventually voting for independence. The main obstacle to attain that scenario, though, is the lack of interest of the Spanish government and of European institutions in helping such a binding referendum over self-determination happen any time soon.

\section{Disclosure statement}

No potential conflict of interest was reported by the author(s). 


\section{ORCID}

X. Puig (D) http://orcid.org/0000-0001-6525-0498

J. Ginebra (1D) http://orcid.org/0000-0001-9521-9635

\section{References}

Balcells, L. (2007). Es el voto nacionalista un voto de proximidad o un voto de compensación? Una nueva aproximación espacial al voto en dos dimensiones. Revista Española de Ciencia Política, $16,61-88$.

Brown, P. J., \& Payne, C. D. (1986). Aggregate data, ecological regression, and voting transitions. Journal of the American Statistical Association, 81(394), 452-460. https://doi.org/10.1080/ 01621459.1986 .10478290

Cleave, N., Brown, P. J., \& Payne, C. D. (1995). Evaluation of methods for ecological inference. Journal of the Royal Statistical Society. Series A (Statistics in Society), 158(1), 55-72. https:// doi.org/10.2307/2983403

Colomer, J. M. (1998). The Spanish 'state of autonomies': Non-institutional federalism. West European Politics, 21(4), 40-52. https://doi.org/10.1080/01402389808425270

Downs, W. M. (2003). El Parlament de Catalunya: A model for regional assertiveness in the EU? South European Society and Politics, 8(3), 33-64. https://doi.org/10.1080/136087408085 39655

Freedman, D. A. (2001). Ecological inference and the ecological fallacy. In N. Smelser, \& P. Baltes (Eds.), International Encyclopedia of the Social and Behavioral Sciences (vol. 6, pp. 4027-4030). Elsevier.

Glynn, A. N., \& Wakefield, J. (2010). Ecological inference in the social sciences. Statistical Methodology, 7(3), 307-322. https://doi.org/10.1016/j.stamet.2009.09.003

Goodman, L. (1953). Ecological regressions and the behavior of individuals. American Sociological Review, 18(6), 663-666. https://doi.org/10.2307/2088121

Goodman, L. (1959). Some alternatives to ecological correlation. American Journal of Sociology, 64 (6), 610-625. https://doi.org/10.1086/222597

Greiner, D. James, \& Quinn, K. M. (2009). $R \times C$ ecological inference: Bounds, correlations, flexibility and transparency of assumptions. Journal of the Royal Statistical Society: Series A (Statistics in Society), 172(1), 67-81. https://doi.org/10.1111/j.1467-985X.2008.00551.x

Guibernau, M. (2013). Secessionism in Catalonia: After democracy. Ethnopolitics, 12(4), 368-393. https://doi.org/10.1080/17449057.2013.843245

Guibernau, M. (2014). Prospects for an independent Catalonia. International Journal of Politics, Culture and Society, 27(1), 5-23. https://doi.org/10.1007/s10767-013-9165-4

Hawkes, A. G. (1969). An approach to the analysis of electoral swing. Journal of the Royal Statistical Society. Series A (General), 132(1), 68-79. https://doi.org/10.2307/2343756

Johnston, R. J., \& Pattie, C. J. (2001). On geographers and ecological inference. Annals of the Association of American Geographers, 91(2), 281-282. https://doi.org/10.1111/0004-5608. 00243

Johnston, R. J., \& Pattie, C. J. (2003). Evaluating an entropy-maximizing solution to the ecological inference problem: Split-ticket voting in New Zealand, 1999. Geographical Analysis, 35(1), 1-23. https://doi.org/10.1111/j.1538-4632.2003.tb01098.x

Keating, M., \& Wilson, A. (2009). Renegotiating the state of autonomies: Statute reform and multilevel politics in Spain. West European Politics, 32(3), 536-558. https://doi.org/10.1080/ 01402380902779089

King, G. (1997). A solution to the ecological inference problem. Princeton University Press.

King, G. (2000). Geography, statistics and ecological inference. Annals of the Association of America Geographers, 90(3), 601-606. https://doi.org/10.1111/0004-5608.00214

Lepic, M. (2017). Limits to territorial nationalization in election support for an independenceaimed regional nationalism in Catalonia. Political Geography, 60, 190-202. https://doi.org/10. 1016/j.polgeo.2017.08.003 
Liñeira, R. (2011). Less at stake or a different game? Regional elections in Catalonia and Scotland. Regional and Federal Studies, 21(3), 283-303. https://doi.org/10.1080/13597566.2011.578790

Miller, W. L. (1972). Measures of electoral change using aggregate data. Journal of the Royal Statistical Society. Series A (General), 135(1), 122-142. https://doi.org/10.2307/2345042

Muro, D. (2009). Territorial accommodation, party politics and statute reform in Spain. South European Society and Politics, 14(4), 453-468. https://doi.org/10.1080/13608740903503845

O’Loughlin, J. (2000). Can King's ecological inference method answer a social scientific puzzle: Who voted for the Nazi party in Weimar Germany? Annals of the Association of American Geographers, 90(3), 592-601. https://doi.org/10.1111/0004-5608.00213

Orte, A., \& Wilson, A. (2009). Multi-level coalitions and statute reform in Spain. Regional and Federal Studies, 19(3), 415-436. https://doi.org/10.1080/13597560902957500

Puig, X., \& Ginebra, J. (2014a). A cluster analysis of vote transitions. Computational Statistics and Data Analysis, 70, 328-344. https://doi.org/10.1016/j.csda.2013.10.006

Puig, X., \& Ginebra, J. (2014b). A Bayesian cluster analysis of election results. Journal of Applied Statistics, 41(1), 73-94. https://doi.org/10.1080/02664763.2013.830088

Puig, X., \& Ginebra, J. (2015). Ecological inference and spatial variation of individual behavior: National divide and elections in Catalonia. Geographical Analysis, 47(3), 262-283. https://doi. org/10.1111/gean.12056

Rico, G., \& Liñeira, R. (2014). Bringing Secessionism into the Mainstream: The 2012 regional election in Catalonia. South European Society and Politics, 19(2), 257-280. https://doi.org/10.1080/ 13608746.2014.910324

Robertson, C., Long, J. A., Nathoo, F. S., Nelson, T. A., \& Plouffe, C. C. F. (2014). Assessing quality of spatial models using the structural similarity index and posterior predictive checks. Geographical Analysis, 46(1), 53-74. https://doi.org/10.1111/gean.12028

Rodon, T., \& Guinjoan, M. (2018). When the context matters: Identity, secession and the spatial dimension in Catalonia. Political Geography, 63, 75-87. https://doi.org/10.1016/j.polgeo.2018. 01.004

Rosen, O., Jiang, W., King, G., \& Tanner, M. A. (2001). Bayesian and frequentist inference for ecological inference: The $R \times C$ case. Statistica Neerlandica, 55(2), 134-156. https://doi.org/10.1111/ 1467-9574.00162

Serrano, I. (2013a). Just a matter of identity? Support for independence in Catalonia. Regional and Federal Studies, 23(5), 523-545. https://doi.org/10.1080/13597566.2013.775945

Serrano, I. (2013b). Secession in Catalonia: Beyond identity? Ethnopolitics, 12(4), 406-409. https:// doi.org/10.1080/17449057.2013.843249

Wakefield, J. (2004). Ecological inference for 2 x 2 tables. Journal of the Royal Statistical Society: Series A (Statistics in Society), 167(3), 385-445. https://doi.org/10.1111/j.1467-985x.2004. 02046_1.x

\section{Appendix: Sketch of the model used}

Let the results of the $i$-th area in the first election, with $N_{i}^{1}$ voting age individuals, be denoted by $y_{i}^{1}=\left(y_{i 1}^{1}, \ldots, y_{i k_{1}}^{1}\right)$, and the results of that area in the second election, with $N_{i}^{2}$ individuals, be denoted by $y_{i}^{2}=\left(y_{i 1}^{2}, \ldots, y_{i k_{2}}^{2}\right)$, where $k_{1}$ and $k_{2}$ are the number of options available in each election.

To allocate the $n$ areas into clusters one introduces a vector of latent variables, $\zeta=\left(\zeta_{1}, \ldots, \zeta_{n}\right)$, where $\zeta_{i}$ is such that $\zeta_{i}=r$ whenever the $i$-th area belongs to the $r$-th cluster and $\pi\left(\zeta_{i}=r \mid \varpi\right)=\varpi_{r}$ for $r=1, \ldots, s$, where $\varpi=\left(\varpi_{1}, \ldots, \varpi_{s}\right)$ are weights determining the proportion of areas belonging to each cluster, and where $s$ is the number of clusters.

One assumes that all areas in the $r$-th cluster share the same average voting behaviour, $\theta_{r}^{1}=\left(\theta_{r 1}^{1}, \ldots, \theta_{r k_{1}}^{1}\right)$, with $\sum_{j=1}^{k_{1}} \theta_{r j}^{1}=1$, where $\theta_{r j}^{1}$ is the probability that an individual in the $r$-th cluster chooses the $j$-th option in the first election, and that $y_{i}^{1}$ is multinomially distributed, $\operatorname{Mult}\left(N_{i}^{1}, \theta_{\zeta_{i}}^{1}\right)$. 
One also assumes that the results of the second election in the $i$-th area, $y_{i}^{2}=\left(y_{i 1}^{2}, \ldots, y_{i k_{2}}^{2}\right)$, are $\operatorname{Mult}\left(N_{i}^{2}, \theta_{\zeta_{i}}^{2}\right)$ distributed, and that in the second election the $i$-th area belongs to the same $\zeta_{i}$-cluster as in the first election. To relate the results of a given area in the second election to the ones in the first election, one defines $\beta_{j l}^{r}$ to be that an individual in cluster $r$ who is known to have chosen the $j$ th option in the first election chooses the $l$-th option in the second election. That leads one to consider the $k_{1} \times k_{2}$ vote-switch matrix for cluster $r, B_{r}$, with all its rows, $\beta_{j}^{r}=\left(\beta_{j 1}^{r}, \ldots, \beta_{j k_{2}}^{r}\right)$, adding up to one, that links $\theta_{i}^{2}$ with $y_{i}^{1}$ through $\theta_{i}^{2}=p_{i}^{1} B_{\zeta_{i}}$, for $i=1, \ldots, n$, where $p_{i}^{1}=\left(y_{i 1}^{1} / N_{i}^{1}, \ldots, y_{i k_{1}}^{1} / N_{i}^{1}\right)$.

The Bayesian approach requires the choice of prior distributions for the parameters. Here reference independent uniform priors on the simplex are used for each $\theta_{r}^{1}$, with $r=1, \ldots, s$, for $\varpi$, and for each one of the rows of $B_{r}, \beta_{j}^{r}$ with $j=1, \ldots, k_{1}$. To update the model the WinBugs MCMC implementation has been used, and a sensitivity to the prior analysis is carried out, finding that the total counts in the areas, and the number of areas, are large enough to guarantee that posterior distributions are barely affected by the prior choices. 